\title{
P-207
}

\section{Effect of Different Solvents Extraction on Antioxidant Activity of Ipomoea Aquatica}

\author{
Lawal Umar $^{\mathrm{a}}$, Faridah Abas ${ }^{\mathrm{a}, \mathrm{b},{ }^{*}}$, Alfi Khatib ${ }^{\mathrm{a}, \mathrm{b}}$ and Intan Safinar Ismail ${ }^{\mathrm{b}}$ \\ ${ }^{a}$ Department of Food Science, Faculty of Food Science and Technology, Universiti Putra Malaysia, 43400 Serdang, \\ Selangor, Malaysia; ${ }^{b}$ Laboratory of Natural Products, Institute of Bioscience, Universiti Putra Malaysia, 43400 \\ Serdang, Selangor, Malaysia; E-mail: faridah@food.upm.edu.my
}

\begin{abstract}
Antioxidants play an important role in inhibiting and scavenging free radicals, thus providing protection to human against infections and degenerative diseases. Current researchers are now directed towards natural antioxidants of plants origin due to safe therapeutics. Ipomoea aquatica Forsk is a green leafy vegetable that rich with vitamins, amino acids and also health benefits. The present study was designed to investigate the antioxidant activity of two types of Ipomoea aquatica cultivars namely narrow leaf (NL) and broad leaf (BL) cultivars. The effect of solvent type on the activity was also investigated, the solvent systems used was distilled water, pure methanol, ethanol, and their aqueous solution at 30\%, 50\% and $70 \%$ concentrations. The extracts were tested for their total phenolic content, ferric reducing ability in plasma (FRAP) and 1,1diphenylpicryl-hydrazyl (DPPH). Ethanol and methanol extracts of Ipomoea aquatica have higher antioxidant activity than water extracts. Results showed that the optimal conditions for DPPH was obtained from Ipomoea aquatica BL extracted with methanol $70 \%$ having $\mathrm{IC}_{50}$ value of $(0.099 \mathrm{mg} / \mathrm{ml} \pm 0.3)$ followed by Ipomoea aquatica $\mathrm{NL}$ extracted with $70 \%$ ethanol $(0.127$ $\mathrm{mg} / \mathrm{ml} \pm 0.2$ ). The total phenolic content of I. aquatica $\mathrm{NL}$ and $I$. aquatica BL $70 \%$ methanolic extracts were found to be highest compare to other extracts, with values of $1.890 \mathrm{mg} \mathrm{GAE} / \mathrm{mg}$ DW and $1.987 \mathrm{mg} \mathrm{GAE} / \mathrm{mg}$ DW extract, respectively.
\end{abstract}

Keywords: Antioxidant, total phenolic content, Ipomoea aquatica. 